\title{
Erratum
}

\section{Seasonal influence on the reproductive performance of swine in the humid zone of Ghana}

\section{J.D. Kabuga and S.Y. Annor}

Department of animal Science, University of Science and Technology, Kumasi, Ghana

Received October 22, 1990; revised June 26, 1991; accepted July 2, 1991

Int J Biometeorol (1991) 35:208-213

There was an error in the legend to Fig. 1 of the above manuscript. The legend should read: annual cycle of some climatic variables. A Minimum $(\bullet \bullet \bullet)$ and maximum $(\square-\square)$ relative humidity and minimum $\left(\Delta^{---} \triangle\right)$ and maximum $\left(\mathrm{O}_{--}-\mathrm{O}\right)$ temperature. B Rainfall. The data shown are mean monthly values.
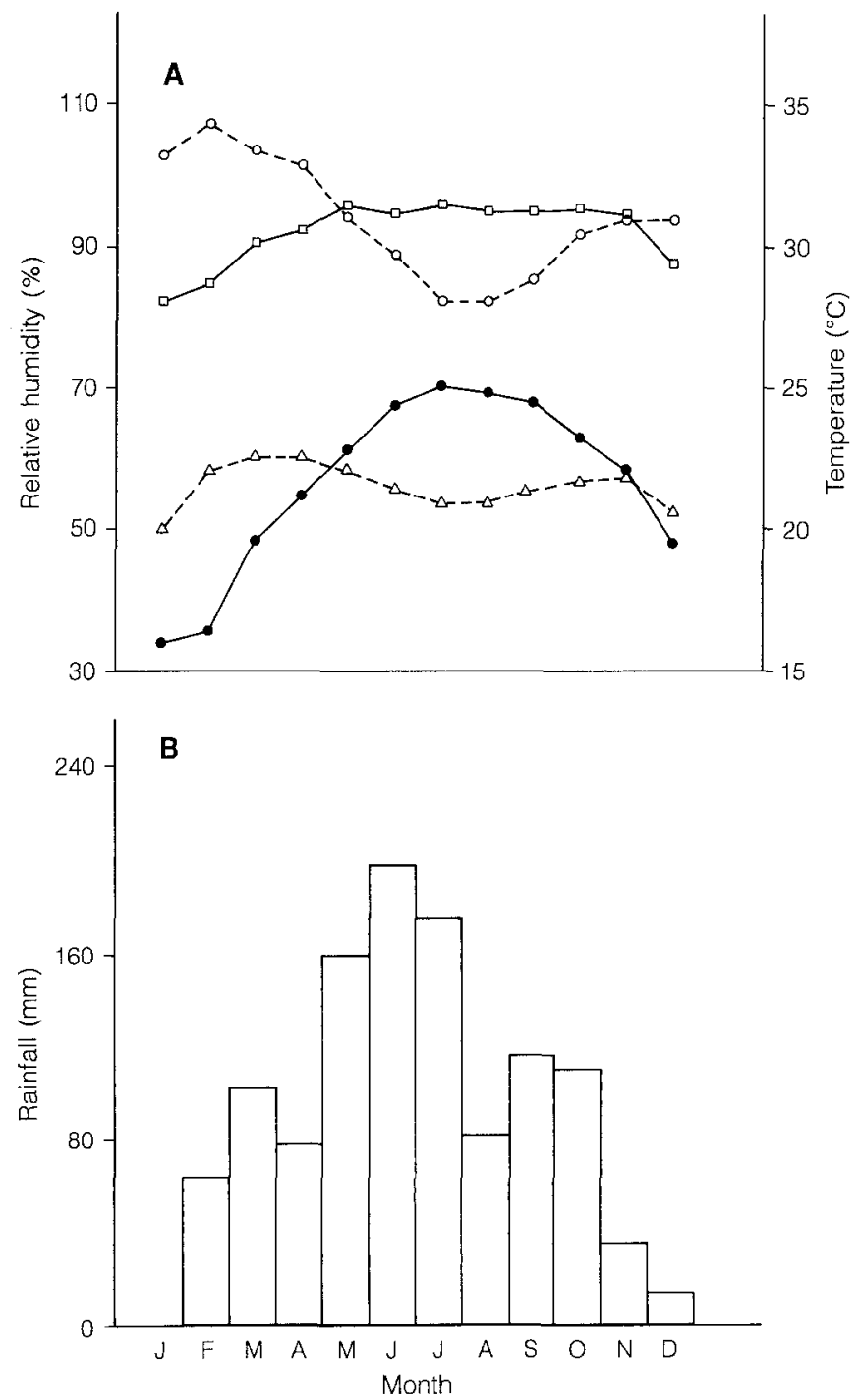